\title{
THE EFFECT OF PREOPERATIVE METHYLPREDNISOLONE ON PULMONARY FUNCTION AND PAIN AFTER LUNG OPERATIONS
}

Dennis Bigler, $\mathrm{MD}^{\mathrm{a}}$

Torsten Jonsson, $\mathrm{MD}^{\mathrm{a}}$

Johnny Olsen, $\mathrm{MD}^{\mathrm{b}}$

Jørgen Brenøe, MD ${ }^{b}$

Kåre Sander-Jensen, $\mathrm{MD}, \mathrm{PhD}^{\mathrm{b}}$
Thirty-six patients undergoing elective thoracotomy with pulmonary resection with the use of combined epidural and general anesthesia were randomized into a double-blind study to receive a single intravenous preoperative dose of methylprednisolone $25 \mathrm{mg} / \mathrm{kg}$ body weight or a placebo (saline solution). Postoperative pain relief consisted of epidural morphine $4 \mathrm{mg}$ and paracetamol $1 \mathrm{gm}$ three times a day for 4 days. Postoperative pulmonary function (peak expiratory flow rate, forced expiratory volume in first second, forced vital capacity) was evaluated on days 1, 2, 3, 4, and 7 and after 1 month. The value obtained after 1 month served as the control value. Pain score at rest and during cough was evaluated after 4 and 8 hours and on days 1, 2, 3, and 4. Pulmonary function was reduced after operation to the same degree in the steroid and placebo group: $42 \%$ versus 41\% for forced expiratory volume in first second and $38 \%$ versus $39 \%$ for forced vital capacity, compared with control values after 1 month. Pain score was reduced in the steroid group after 4 hours and on day 1 during rest and after 4 and 8 hours and on day 2 during cough, compared with results in the placebo group $(p<0.05)$. In the steroid group three patients underwent reoperation because of leakage through the chest wall incision. In conclusion, administration of a single preoperative dose of methylpred. nisolone did not affect the postoperative reduction in pulmonary function after thoracotomy despite attenuated pain response, and the results do not warrant steroid administration before lung operation. ( $J$ Thorac Cardiovasc Surg 1996;112:142-5) mpaired ventilatory function seen after thoracotomy is not only caused by the pulmonary resection but also by postoperative pain and the surgical trauma. ${ }^{1}$ The clinical importance of the endocrine and metabolic response to surgical trauma is still uncertain, but it has been assumed that this socalled surgical stress response is partly responsible for the temporary reduction in pulmonary function seen after lung operations and other types of major operations. ${ }^{2,3}$ Recent studies have indicated that preoperative injection of methylprednisolone in combination with epidural analgesia and indometh-

From the Departments of Anesthesiology a and Cardiothoracic Surgery, ${ }^{b}$ Gentofte University Hospital, Copenhagen, Denmark.

Received for publication May 22, 1995; accepted for publication August 30, 1995.

Address for reprints: Dennis Bigler, MD, Department of Anaesthesiology, Gentofte Hospital, Niels Andersens Vej 65, DK2900 Hellerup, Copenhagen, Denmark.

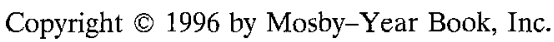

$0022-5223 / 96 \$ 5.00+0 \quad \mathbf{1 2 / 1 / 6 8 9 1 3}$ acin may inhibit the surgical stress response and thereby partly abolish the postoperative reduction in pulmonary function and improve pain relief after abdominal operations., 5

The aim of the present study was to evaluate in a randomized, double-blind fashion whether a single preoperative dose of methylprednisolone would attenuate the postoperative temporary reduction in pulmonary function and reduce pain after thoracotomy. In addition, the study would measure the degree of the temporary decrease in pulmonary function after lung resection.

\section{Patients and methods}

Thirty-six patients undergoing elective thoracotomy with pulmonary resection with the use of combined epidural and general anesthesia were included in the study. The protocol was approved by the local ethics committee and informed patient consent was obtained before operation. The patients were randomized in a double-blind manner to receive preoperative methylprednisolone 25 $\mathrm{mg} / \mathrm{kg}$ body weight (18 patients) or placebo (saline solution; 18 patients) intravenously 30 minutes before the start 
Table I. Preoperative patient data and type of operation

\begin{tabular}{lcc} 
& \multicolumn{1}{c}{ Steroid group } & Placebo group \\
\hline Sex (F/M) & $7 / 11$ & $2 / 16$ \\
Age (yr) & $66(33-76)$ & $62(50-75)$ \\
Weight $(\mathrm{kg})$ & $60(40-83)$ & $71(43-90)$ \\
Height $(\mathrm{cm})$ & $167(156-180)$ & $173(158-183)$ \\
PEF (L/min) & $317(128-700)$ & $370(211-590)$ \\
FVC (L) & $2.4(1.8-5.0)$ & $3.6(2.6-4.7)$ \\
FEV $(\mathrm{L})$ & $1.8(1.2-3.3)$ & $2.3(1.6-3.8)$ \\
Lobectomy & 11 & 11 \\
Pneumonectomy & 6 & 5 \\
Wedge resection & 1 & 2 \\
\hline
\end{tabular}

Median values are given with range in parenthesis. $F$, Female; $M$, male.

of operation. Patients with signs of infection, diabetes mellitus, or receiving treatment with nonsteroidal antiinflammatory drugs or steroids were not included in the study and patients who did not have pulmonary resection because of inoperability were excluded from the study and replaced by other patients.

All patients received morphine (5 to $10 \mathrm{mg}$ ) and scopolamine (0.2 to $0.4 \mathrm{mg}$ ) as premedication and had a thoracic epidural catheter inserted at the $\mathrm{T} 5$ to $\mathrm{T} 7$ vertebral level before the start of operation. Anesthesia was then induced with thiopental ( 4 to $5 \mathrm{mg} / \mathrm{kg}$ ) followed by pancuronium $(0.1 \mathrm{mg} / \mathrm{kg})$ to facilitate intubation with a double-lumen endobronchial tube and maintained with enflurane in oxygen as required. After the patient was placed in the lateral position an epidural bolus of bupivacaine $4 \mathrm{ml}(5 \mathrm{mg} / \mathrm{ml})$ and morphine $2 \mathrm{ml}(1 \mathrm{mg} / \mathrm{ml})$ was given followed by continuous infusion of bupivacaine 4 to $5 \mathrm{ml} / \mathrm{hr}(5 \mathrm{mg} / \mathrm{ml})$.

The thoracotomy was done by a posterolateral incision between the fifth and sixth ribs, and chest tubes were inserted between the ninth and tenth ribs in patients undergoing lobectomy. The latissimus muscle was divided and the serratus anterior muscle was partially transected. After operation the patients were extubated and transferred to the intensive care unit. Postoperative pain relief consisted of continuous epidural infusion of 4 to $5 \mathrm{ml} / \mathrm{hr}$ of bupivacaine $(5 \mathrm{mg} / \mathrm{ml})$ for the first 12 hours and thereafter epidural morphine $4 \mathrm{mg}$ and paracetamol $1 \mathrm{gm}$ per os three times a day for 4 days. The postoperative pulmonary function was estimated by forced vital capacity (FVC), forced expiratory volume in first second $\left(\mathrm{FEV}_{1}\right)$, and peak expiratory flow rate (PEF) on days 1, 2, 3, 4, and 7 and after 1 month. Pain score at rest and during cough was obtained 4 and 8 hours after operation and on days 1,2,3, and 4 with a verbal five-point scale of pain assessment $(0$, no pain; 1 , slight; 2 , moderate; 3 , severe; 4 , unbearable pain). The postoperative temporary reduction in pulmonary function was found by comparison of the postoperative minimal measurement with the measurement obtained after 1 month.

Statistical analysis. We accepted a risk of type I error at 0.05 and a risk of type II error at 0.2 . With an estimated standard deviation of 1 on pain score and 0.15 on lung function and the smallest difference between the means not to be overlooked being 1 in pain

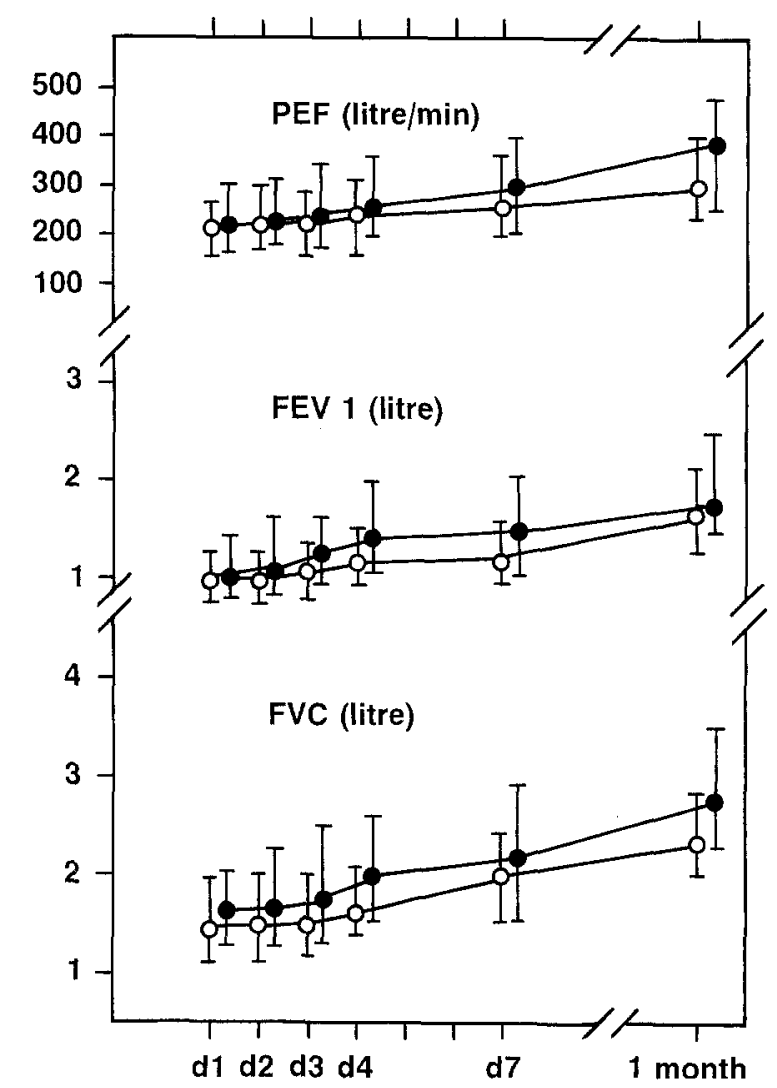

Fig. 1. Postoperative pulmonary function after thoracotomy with pulmonary resection. Median and 25th to 75th percentile values are shown. Open circles, Steroid group; closed circles, placebo group; $d$, day.

score and 0.15 in lung function, the number of patients in each group was calculated to 15 patients (MEDSTAT $^{*}$ ). Fisher's exact test and the Mann-Whitney test for unpaired data were used to compare preoperative patient data. Friedman's test for paired data was used to compare data within the same group and differences between groups were compared with the Kruskal-Wallis test for unpaired data. A $p$ value less than 0.05 was considered significant.

\section{Results}

Patient data and preoperative values are given in Table I. The minimum value of postoperative pulmonary function was seen on days 1 and 2 and function increased thereafter in all patients (Fig. 1). The pulmonary function was reduced after operation to the same degree in the steroid and placebo group: $42 \%$ versus $41 \%$ for $\mathrm{FEV}_{1}$ and $38 \%$ versus

*MEDSTAT - statistical program for the analysis of the results of controlled therapeutic trials and other types of clinical research, by H. R. Wulff and P. Schlicting, Medical Department C, Herlev University Hospital, 2730 Herlev, Denmark. 


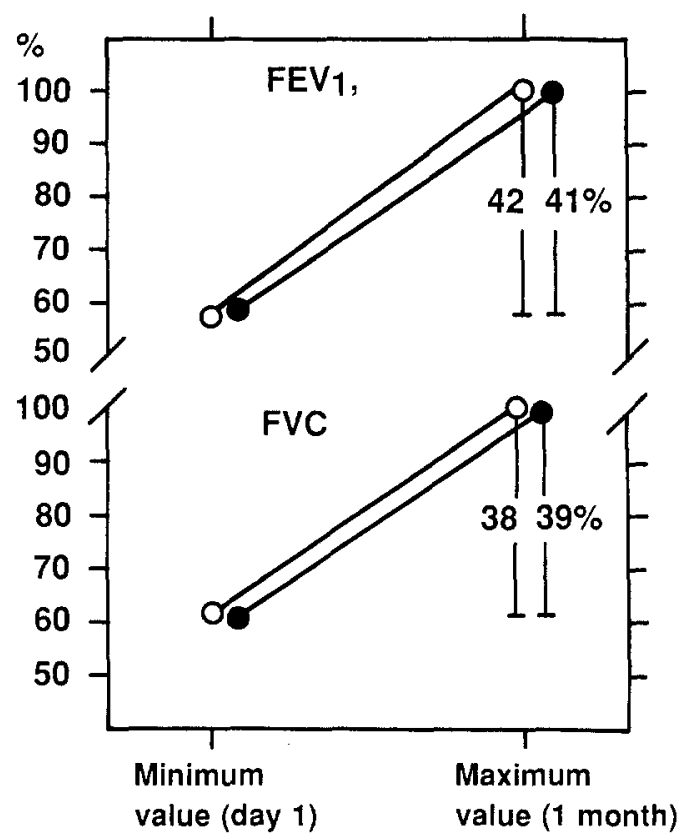

Fig. 2. Temporary postoperative reduction in pulmonary function after thoracotomy with pulmonary resection. Mean values and percentage are shown. Value after 1 month served as control value $(100 \%)$. Open circles, Steroid group; closed circles, placebo group.

$39 \%$ for FVC, compared with the control value obtained 1 month after operation (Fig. 2). Median pain score was reduced in the steroid group at 4 hours and on day 1 during rest and at 4 and 8 hours and on day 2 during cough, compared with scores in the placebo group $(p<0.05)$ (Fig. 3).

Severe complications were seen in six patients. In the steroid group three patients underwent reoperation because of leakage of serous fluid through the chest wall incision and one patient died 7 days after operation in the intensive care unit of respiratory insufficiency after aspiration. In the placebo group one patient had a cerebral stroke on day 4 and was later discharged from the hospital with a hemiplegia. One patient died on postoperative day 10 of myocardial infarction.

\section{Discussion}

This study showed that the temporary decrease in pulmonary function after thoracotomy per se is about $40 \%$. We were not able to demonstrate any beneficial effect on this temporary postoperative reduction in pulmonary function of a single dose of preoperative methylprednisolone although the pain

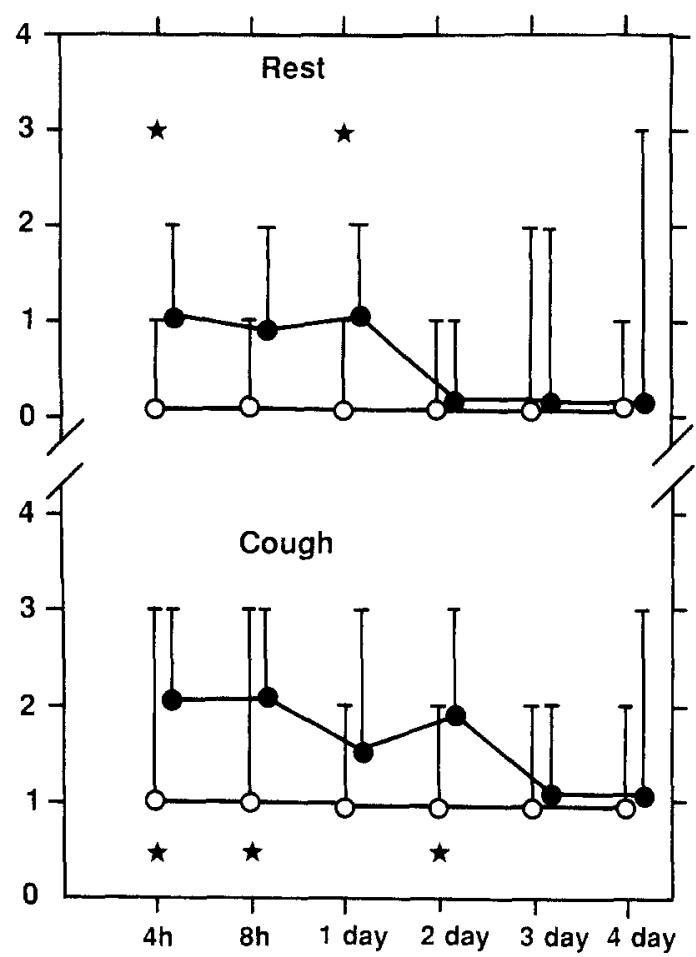

Fig. 3. Postoperative pain score after thoracotomy with pulmonary resection. Verbal pain assessment assigned score of 0 for no pain, 1 for light pain, 2 for moderate, 3 for severe, and 4 for unbearable. Median and upper range scores during rest and cough are shown. Open circles, Steroid group; closed circles, placebo group; $h$, hours. Stars indicate significant difference between groups.

response after thoracotomy was attenuated during the first 24 hours.

Several factors such as postoperative pain, the surgical stress trauma, and postoperative inhibition of diaphragmatic function may contribute to the ventilatory dysfunction seen after major operations. ${ }^{1,6}$ The present finding of an attenuated pain response without influence on the postoperative reduction in pulmonary function is in accordance with findings of some previous studies concerning abdominal operations. ${ }^{7-9}$ Thus pain does not seem to be of major importance in the pathogenesis of postoperative reduction of pulmonary function.

It is noteworthy that only a few studies have been done in which the dose of prednisolone was as high as in the present study. In those trials concerning gastrointestinal tract operations indomethacin had also been given in addition to prednisolone. The results from those studies indicated that high doses of prednisolone partly abolish the postoperative 
impairment in pulmonary function by modifying the systemic response to operation. ${ }^{4,5}$ This effect may be a result of the addition of indomethacin. However, in a recent study we failed to show any additional effect on pain relief and pulmonary function of a nonsteroidal antiinflammatory drug (piroxicam) given in combination with epidural analgesia after thoracotomy. ${ }^{10}$ In addition, a previous study demonstrated that the combination of epidural analgesia and systemic indomethacin could eliminate pain but not the systemic response after cholecystectomy. ${ }^{8}$

Furthermore steroids are potent inhibitors of all the metabolites of the arachidonic acid cascade and of several metabolically active macrophage-derived peptides and remain the only therapeutic agents with potential multi-inhibitory effects on the various components of the stress response. ${ }^{3,11}$ Thus it seems reasonable to assume that an eventual abolishment of the temporary decrease in pulmonary function after abdominal operation is a result of the administration of prednisolone.

It could be speculated that the systemic response to lung operation is different from the response seen after abdominal operations. The immunologic and endocrine changes after lung operation have been found to be almost similar to those observed after other types of major operations, ${ }^{2}$ but it has recently been demonstrated that methylprednisolone administered immediately before anesthesia does not modify the systemic interleukin-6 response to lung operation and the investigators in that study did not recommend steroid therapy in infection-free patients undergoing operation. ${ }^{12}$ This may be the reason that methylprednisolone in the present study had no influence on the postoperative reduction in pulmonary function after lung operation.

The glucocorticoids may have potential side effects on wound healing and immune function despite administration of only a single dose. In this study three patients in the steroid group required reoperation because of leakage of fluid through the chest wall incision, whereas no patient in the control group required reoperation. Although the difference was not significant, the steroid may have contributed to this complication inasmuch as similar wound complications have been reported in a previous study. ${ }^{5}$
In conclusion, this study demonstrated a $40 \%$ temporary decrease in pulmonary function after thoracotomy with lung resection. This reduction was not influenced by a preoperative steroid injection, although the pain response was attenuated during the first 24 hours. The results of this study suggest that steroid administration before lung operation is not warranted.

\section{REFERENCES}

1. Craig DB. Post-operative recovery of pulmonary function. Anesth Analg 1981;60:46-52.

2. Tønnesen E, Hohndorf K, Lerbjerg G, Christensen NJ, Huttel MS, Andersen K. Immunological and hormonal responses to lung surgery during one-lung ventilation. Eur $\mathrm{J}$ Anaesthesiol 1993;10:189-95.

3. Kehlet H. Surgical stress: the role of pain and analgesia. Br J Anaesth 1989;63:189-95.

4. Schuize S, Møller IW, Bang U, Rye B, Kehlet H. Effect of combined prednisolone, epidural analgesia and indomethacin on pain, systemic response and convalescence after cholecystectomy. Acta Chir Scand 1990;156:203-9.

5. Schulze S, Sommer P, Bigler D, et al. Effect of combined prednisolone, epidural analgesia, and indomethacin on the systemic response after colonic surgery. Arch Surg 1992;127: 325-31.

6. Fratacci MD, Kimball WR, Wain JC, Kacmarek RM, Polaner DM, Zapol WM. Diaphragmatic shortening after thoracic surgery in humans. Anesthesiology 1993;79:654-65.

7. Scott NB, Mogensen T, Bigler D, Lund C, Kehlet H. Thoracic extradural $0.5 \%$ bupivacaine with or without morphine: effects on quality of blockade, lung function and the surgical stress response. Br J Anaesth 1989;62:253-7.

8. Schulze S, Roikjaer O, Hasselstrøm L, Jensen NH, Kehlet H. Epidural bupivacaine and morphine plus systemic indomethacin eliminates pain but not the systemic response and convalescence after cholecystectomy. Surgery 1988;103: 321-7.

9. Bigler D, Dirkes W, Hansen R, Rosenberg J, Kehlet H. Effects of thoracic paravertebral block with bupivacaine versus combined thoracic epidural block with bupivacaine and morphine on pain and pulmonary function after cholecystectomy. Acta Anaesthesiol Scand 1989;33:561-4.

10. Bigler D, Møller J, Kamp-Jensen M, Berthelsen P, Hjortsø NC, Kehlet $\mathrm{H}$. Effect of piroxicam in addition to continuous thoracic epidural bupivacaine and morphine on postoperative pain and lung function after thoracotomy. Acta Anaesthesiol Scand 1992;36:647-50.

11. Munck A, Guyre PM, Holbrook NJ. Physiological functions of glucocorticoids in stress and their relation to pharmacological actions. Endocr Rev 1984;5:25-44.

12. Tønnesen E, Wanscher M, Hohndorf $\mathrm{K}$, et al. Effect of methylprednisolone on the cytokine response in patients undergoing lung surgery. Acta Anesthesiol Scand 1993;37: 410-4. 